\title{
INSERÇÃO NO MERCADO DE TRABALHO: TRAJ ETÓRIA DE EGRESSOS DE UM CURSO DE GRADUAÇÃO EM ENFERMAGEM ${ }^{a}$
}

\author{
J ob market placement: professional traj ectory of nursing graduates \\ Inclusión en el mercado de trabaj o: trayectoria de los graduados de una licenciatura \\ en enfermería
}

Bruna Helena de Jesus'

Diana Coelho Gomes ${ }^{2}$

Lia Beatriz Bortolotto Spillere ${ }^{3}$

Marta Lenise do Prado ${ }^{4}$

Bruna Pedroso Canever ${ }^{5}$

\section{RESUMO}

Trata-se de um estudo exploratório-descritivo, com abordagem qualitativa, que teve como objetivo analisar a contribuição do processo de formação crítico-criativa na inserção dos Enfermeiros no mercado de trabalho. A coleta de dados deu-se em agosto e setembro de 2011, por meio de entrevistas semiestruturadas, realizadas com 15 egressos do Curso de Graduação em Enfermagem da Universidade Federal de Santa Catarina (UFSC), que se graduaram nos últimos dois anos antecedentes a esse estudo e que estão inseridos no mercado de trabalho. Os resultados demonstram que o desenvolvimento de competências para a liderança, gestão de pessoas, relações interpessoais e o preparo para a docência, durante a graduação, são elementos facilitadores da inserção no mercado de trabalho. Diante dos obstáculos, os egressos sentiram-se estimulados a dar continuidade ao processo de aprendizado, conscientizando-se da importância da educação permanente como ferramenta para novas possibilidades no mercado de trabalho e fundamental para mudança da realidade.

Palavras-chave: Mercado de trabalho. Educação em Enfermagem. Educação superior. Enfermagem.

\begin{abstract}
Exploratory descriptive study with qualitative approach, which aims to analyze the contribution of the critical-creative training process in the placement of nurses in the job market. Data collection occurred in August and September of 2011, through structured interviews conducted with 15 graduates of the undergraduate Nursing Degree of the Federal University of Santa Catarina (UFSC). These nurses graduated in the two years before this study was made and they are already inserted in the job market. The results demonstrate that the development of leadership, people management and personal relations skills, in addition to teaching preparation, improve the integration into the labor market. Given the obstacles, the graduates felt encouraged to continue the learning process, becoming aware of the importance of continuing education as a fundamental tool for the changing reality.
\end{abstract}

Keywords: Job Market. Education, Nursing. Education, Higher. Nursing

\section{Resumen}

Se trata de un estudio exploratorio descriptivo, con abordaje cualitativo, cuyo objetivo es analizar la contribución del proceso de crítica-creativa en la integración de las enfermeras en el mercado laboral. La recolección de datos tuvo lugar en agosto y septiembre de 2011, a través de entrevistas estructuradas realizadas con 15 egresados de la Licenciatura en Enfermería, de la Universidad Federal de Santa Catarina (UFSC), que se graduaron en los últimos dos años antes del estudio y se insertaron en el mercado de trabajo. Los resultados demuestran que el desarrollo de habilidades para el liderazgo, la gestión de personal, las relaciones interpersonales y la preparación para la docencia identificados como los facilitadores de la integración en el mercado laboral. Teniendo en cuenta los obstáculos, los graduados se quedaron alentados a continuar el proceso de aprendizaje, tomando conciencia de la importancia de la educación continúa como una herramientafundamental para cambiar la realidad.

Palabras clave: Mercado de trabajo. Educación en Enfermería. Educación Superior. Enfermería.

'Enfermeira. Membro do Grupo de Pesquisa em Educação em Enfermagem e Saúde (EDEN). Florianópolis - SC. Brasil. E-mail: brunahelena_j@yahoo.com.br, ${ }^{2}$ Enfermeira. Professora substituta do Departamento de Enfermagem da Universidade Federal de Santa Catarina (UFSC). Membro do Grupo de Pesquisa em Educação em Enfermagem e Saúde (EDEN). Florianópolis - SC. Brasil. E-mail: alodiana@yahoo.com.br;3Enfermeira. Membro do Grupo de Pesquisa em Educação em Enfermagem e Saúde (EDEN). Florianópolis - SC. Brasil. E-mail: liaspillere@hotmail.com;“Doutora em Enfermagem. Docente do Departamento de Enfermagem e Programa de Pós-Graduação em Enfermagem da Universidade Federal de Santa Catarina (PEN/ UFSC). Pesquisadora do CNPq. Vice- líder do Grupo de Pesquisa EDEN. Florianópolis - SC. Brasil. E-mail: mpradop@ccs.ufsc.br; ${ }^{5}$ Doutoranda em Enfermagem pelo PEN/UFSC. Professora substituta do Departamento de Enfermagem da UFSC. Membro do Grupo de Pesquisa EDEN. Florianópolis SC. Brasil. E-mail: olabruna@gmail.com 


\section{INTRODUÇÃO}

A transição da academia para o campo de trabalho é um processo desafiador para os enfermeiros recém-formados. A preocupação com esse momento é algo comumente observado nos graduandos e egressos; há, muitas vezes, ansiedade por terem de assumir as responsabilidades atribuídas ao enfermeiro e as novas demandas de atitudes e competências. ${ }^{1}$

Diante disso, as Instituições de Ensino Superior (IES) vêm repensando a formação dos enfermeiros, com intuito de adequar os Projetos Pedagógicos (PP), conforme preconizado nas Diretrizes Curriculares Nacionais (2001), em que é estabelecido como perfil do profissional/egresso um "Enfermeiro com formação generalista, humanista, crítica, reflexiva" e que possua como competências gerais a capacidade de atenção à saúde, tomada de decisões, habilidade de liderança, administração e gerenciamento e educação permanente. ${ }^{2}$

Apesar da reformulação dos PP, a escassez de estudos acerca da percepção dos enfermeiros, quanto à formação e inserção no cenário de atuação profissional, demonstra uma fragilidade no que tange ao reconhecimento da contribuição da formação de sujeitos críticos-reflexivos e a inserção no mercado de trabalho.

0 grande desafio para os educadores consiste em formar profissionais aptos a responderem às demandas de uma sociedade complexa e inserirem-se em um mercado de trabalho competitivo. Dentro deste contexto, porém, a formação não deve apenas privilegiar a entrada e permanência no mercado de trabalho, mas também enfatizar uma educação humanista, que promova a construção de sujeitos críticos, autônomos e com capacidade de transformação.

Desta forma, surgiram os seguintes questionamentos: Como ocorre a inserção do egresso de enfermagem no mercado de trabalho? Quais os passos percorridos na sua trajetória? Quais as facilidades e/ou dificuldades enfrentadas por estes profissionais?

É necessário, desse modo, ampliar o conhecimento acerca da inserção dos egressos do curso de graduação em Enfermagem no mercado de trabalho, para que seja possível reconhecer as dificuldades e as facilidades, os mecanismos de enfrentamento e como a formação tem contribuído durante esse processo.

No ambiente supracitado, o presente estudo teve como objetivo analisar a contribuição do processo de formação críticocriativa na inserção dos enfermeiros no mercado de trabalho.

\section{MÉTODO}

0 estudo corresponde a uma pesquisa exploratóriadescritiva com abordagem qualitativa dos dados. A pesquisa foi realizada com 15 egressos do Curso de Graduação em Enfermagem da Universidade Federal de Santa Catarina (UFSC), os quais se graduaram nos últimos dois anos antecedentes a esse estudo (2009 e 2010) e que estão inseridos no mercado de trabalho atuando como enfermeiros.

0 contato com os participantes ocorreu mediante a solicitação à Secretaria do Curso de Graduação em Enfermagem da lista com os nomes completos dos graduados no período desejado para o estudo (2009-2010). Essa lista foi encaminhada ao Núcleo de Departamento de Pessoal (NPD) da UFSC, o qual forneceu os e-mails pessoais dos egressos cadastrados no sistema da universidade, somando ao total 115 endereços eletrônicos. Dessa forma, o primeiro contanto realizado com os sujeitos deu-se pelo envio de um convite para participar do estudo aos endereços eletrônicos dos egressos, por meio de e-mail criado especialmente para a pesquisa (tccufsc@yahoo.com.br).

Do total de 115 e-mails enviados, somente 10 retornaram. Devido à desatualização dos endereços eletrônicos e dificuldade na localização desses enfermeiros, criou-se uma segunda estratégia de busca de comunicação com os sujeitos. Na tentativa de atualização de seus contatos, foi realizada uma busca em site de relacionamento. Além disso, à medida que eram realizadas as entrevistas, foi solicitado aos participantes que informassem o endereço eletrônico mais atual dos colegas da turma, ou de outros no período estabelecido pelo estudo, com o qual ainda mantinham contato. Os critérios de exclusão foram a não aceitação de participação na pesquisa e não estar inserido no mercado de trabalho.

As entrevistas foram realizadas pelas pesquisadoras em local e data escolhidos pelo entrevistado de acordo com a sua disponibilidade. Essas foram gravadas em arquivo digital, sendo posteriormente transcritas. 0 número de participantes foi definido por meio da saturação dos dados, a partir do momento em que começou a ocorrer a semelhança dos discursos e a reincidência de informações.

A análise dos dados foi realizada conforme proposto por Minayo ${ }^{3}$, seguindo as seguintes etapas: 01 . Ordenação dos dados: transcrições das entrevistas, com releitura do material e organização dos relatos por ordem de entrevista; 02. Classificação dos dados: leitura exaustiva e repetida dos textos e a apreensão das estruturas relevantes das ideias centrais, dos momentos-chave e formação das categorias temáticas, após uma leitura transversal do material; e 03. Análise final: dados foram relacionados com o referencial teórico, buscando responder à questão da pesquisa.

Com a ordenação e classificação dos dados, emergiu a categoria: Itinerário de inserção no mercado de trabalho, com três subcategorias: "Buscando o meu caminho: entrada no mercado de trabalho", "Chegando a primeira pousada: facilidades e dificuldades do ingresso no mercado de trabalho", "Planejando a próxima viagem: em busca da qualificação profissional".

A pesquisa em questão obteve parecer favorável do Comitê de Ética em Pesquisa em Seres Humanos da Universidade Federal de Santa Catarina, registrado sob o 
número 1942/11, conforme preconizado pela Resolução 196/ 95 do Conselho Nacional de Saúde.

A aceitação dos egressos para participação da pesquisa foi obtida através da assinatura do Termo de Consentimento Livre e Esclarecido (TCLE). Foram assegurados, dessa maneira, aos participantes, 0 anonimato, o sigilo das informações e 0 direito à desistência de participação sem qualquer tipo de prejuízo ou sanção. 0 anonimato foi mantido através da identificação pela letra $\mathrm{E}$ (Entrevistado), seguido de uma ordem numérica de 1 a 15.

\section{RESULTADOS E DISCUSSÔES}

\section{Buscando o meu caminho: entrada no mercado de trabalho}

Nessa subcategoria, foram organizados os relatos que contemplam a trajetória do término da graduação, até a entrada no mercado de trabalho (distribuição de currículo, realização de concursos públicos, oportunidades que surgiram, indicações).

Ao saírem da graduação, os egressos da Universidade Federal de Santa Catarina seguiram diversos caminhos para conseguirem uma colocação no mercado de trabalho. De acordo com os relatos abaixo, observa-se que, inicialmente, alguns optaram pela entrega de currículo em diversas instituições:

A minha inserção foi logo depois de formada. É claro que eu mandei currículo para vários lugares e tentei em escola técnica, então eu consegui um contrato temporário no Estado e fui para UTI [...] (E4)

Fiz meu currículo e enviei final de janeiro e início de fevereiro. Só por abril que começaram a chamar, até então nada, a gente fica na expectativa. (E14)

Houve casos em que a conquista do primeiro emprego ocorreu em virtude de prestação de concursos públicos ainda durante a graduação:

O meu primeiro emprego foi aqui no Hospital X. Eu tinha feito esse concurso quando eu ainda estava na graduação, e logo que eu me formei eu fui chamada no concurso e vim trabalhar (E13)

Eu sou contratado público, foi em concurso público, e, na faculdade inteira, ela foi voltada para o SUS, para atenção básica, para PSF e é com isso que eu estou trabalhando no momento. (E10)

A indicação também foi uma maneira de conseguir a entrada no mercado de trabalho, como pode ser observado no descrição abaixo:
Então, essa procura de emprego foi um pouco diferente, porque o médico que é um dos donos da clínica tem contato com uma das professoras aqui do departamento que foi onde ele solicitou um encaminhamento de uma aluna recém-formada que tivesse um conhecimento prático-teórico diferenciado, que é o que ele diz até hoje do enfermeiro não só do papel, da prática também. $E$ eu tive sorte por eles gostarem do meu perfil e gostarem do meu currículo também, e eu fui contratada. (E15)

Os discursos revelam diferentes maneiras encontradas pelos egressos para se inserirem no mercado de trabalho. Em uma pesquisa realizada com 175 egressos de enfermagem de um curso do sudeste do Brasil, $52 \%$ conseguiram o primeiro emprego por meio de processo seletivo; $17,1 \%$, por meio de concursos públicos; e 8,5\%, por indicação de colegas. Assim, é perceptível que o egresso precisa estar bem preparado para a realização de concursos, ter postura profissional adequada e, também, possuir uma boa rede de relacionamentos interpessoais a fim de facilitar o seu ingresso no mercado de trabalho. ${ }^{4}$

Alguns entrevistados associaram a conquista do primeiro emprego não aos seus conhecimentos e habilidades, mas a uma questão de sorte:

Eu tive muita sorte porque, no último ano de graduação, que foi em 2010, eu comecei a prestar concurso público e eu tive a sorte de tirar em primeiro lugar em um dos concursos públicos que eu fiz. (E2)

Facilidade foi que eu nem fiquei desempregada muito tempo porque eu saí da semi-intensiva final de dezembro e em fevereiro eu já estava empregada, então foi uma facilidade, mas acho, também, foi questão de sorte que me chamaram, eu fui bem na entrevista. (E11)

Os relatos demonstram certa insegurança dos egressos em admitir as suas capacidades, atribuindo suas conquistas a uma questão de sorte.

Em alguns relatos, a frustração por não passar em um concurso público foi demonstrada. A fim de contornar essa situação a opção escolhida foi a entrega de currículos em clínicas particulares. Entretanto, a falta de experiência profissional foi uma dificuldade, pois, para a grande maioria das instituições privadas de saúde, esse é um fator de grande importância para a contratação de um profissional. Isso pode ser observado nos relatos abaixo: 
Foi bem difícil; eu me formei e comecei a estudar para concurso. Eu fiquei estudando em casa para concurso, porque eu achei que a minha chance sem experiência profissional seria passando num concurso público, achei que não me aceitariam em uma clínica privada. Depois de um tempo que eu vi que não fui chamada em nenhum concurso [...], então eu comecei a entregar meu currículo nas clínicas particulares. Eu distribuí em algumas, e duas delas me chamaram depois de um tempo, [...] mas infelizmente acabei não sendo aceita apesar de passar em várias etapas, prova e entrevista, por causa da falta de experiência profissional, e isso ficava bem claro. (E7)

Eu fiz alguns concursos. Durante a faculdade eu fui chamada em um concurso [...] e não pude assumir porque estava na sétima fase. Participei no concurso de [...] também não fui chamada, então tu cria expectativa em relação a concurso porque, concursado, o salário é bom. Quando isso não acontece em curto prazo tu ficas assim meio sem chão, mas e agora? Na particular é complicado porque muitas vezes [...] eles te exigem coisas que como recém-formado tu não tem, como uma especialização, experiência, experiência como profissional mesmo, não como estagiária, eu achei complicado. (E11)

0 atual mercado de trabalho dispõe de um número considerável de profissionais, oferecendo às empresas 0 privilégio de escolher os mais capacitados. Dessa forma, os empregadores optam por selecionar aqueles com melhor formação e maior experiência na profissão. ${ }^{4}$

Na busca por um profissional qualificado, percebese, que em muitos casos, ocorre certa confusão entre habilidades para realizar procedimentos técnicos e capacidade técnica. A qualidade profissional está pautada não apenas na habilidade técnica, que consiste na destreza e agilidade para a realização de procedimentos, mas na capacidade que esse profissional possui de utilizar e integrar seus conhecimentos em situações reais do cotidiano de forma ética e com base em evidencias científicas. Pelos relatos supracitados, pode-se deduzir que muitos dos egressos, sem experiências profissionais anteriores, não têm a oportunidade de demonstrar seus conhecimentos e habilidades. ${ }^{5,}$

Houve relatos nos quais a universidade foi elogiada por preparar bem seus alunos para a inserção no mercado de trabalho:

Eu senti que a UFSC prepara muito bem a gente para o mercado de trabalho, só que está bem concorrido, bem competitivo o mercado, tem muita gente. Está bem difícil. (E3)

Eu acho que a UFSC prepara muito bem para lidar com a equipe, para procurar um emprego, para tudo. É difícil para mim porque, como eu vim trabalhar direto, eu não vi dificuldades para me inserir, e eu mantenho contato com todas as meninas da minha turma, todos estão trabalhando, todos, sem exceção. (E6)

Durante a graduação é de suma importância que a formação, além de priorizar o conhecimento científico e o desenvolvimento de habilidades práticas; busque, também, aproximar seu estudante das exigências do mercado, facilitando a sua transição para o mundo profissional e preparando para as diferentes dificuldades a serem encontradas.

\section{Chegando a primeira pousada: facilidades e dificuldades do ingresso no mercado de trabalho}

A seguinte subcategoria trata das falas a respeito da percepção do egresso ao inserir-se no seu primeiro emprego, sendo destacadas questões referentes à recepção da equipe às facilidades e às dificuldades encontradas no campo de trabalho, a experiências positivas e negativas no seu curso que contribuíram ou não na inserção no mercado de trabalho.

Ao falar do processo de inserção no seu campo de trabalho, muitos relataram a maneira como foram recebidos e de que forma isso influenciou no desempenho de suas funções. Houve descrições em que a equipe teve papel importante tanto para o bom desempenho profissional quanto para a boa adaptação ao local de trabalho. Isso pode ser observado nas seguintes falas:

Está sendo muito bom de trabalhar e também essa enfermeira me recebeu muito bem. Ela me explicou toda a rotina, como que funcionava tudo na unidade, qualquer dúvida que eu tivesse eu podia perguntar para ela, então eu fui muito bem acolhida lá. (E2)

Tinha outra enfermeira que tinha se formado acho que um ano antes de mim. Ela ficava na mesma sala que eu, a gente trabalhava juntas e ela me passou tudo, ela foi muito receptiva, e essa foi uma sorte que eu tive, um ponto positivo, porque quando a gente tem uma equipe receptiva é muito mais fácil essa inserção e esse aprendizado. (E7)

A equipe profissional em um ambiente de trabalho deve prezar a boa relação interpessoal, visto que a adequada interação entre os membros envolvidos irá refletir no cenário de prática. Esses realizam ações coletivas para que seja alcançado um objetivo comum; para isso é preciso o bom 
relacionamento entre os profissionais, o comprometimento de todos, a boa comunicação, a flexibilidade dos sujeitos envolvidos, a motivação e a realização pessoal. ${ }^{6}$

De acordo com o que foi dito acima, fica clara a importância da recepção da equipe, visto que irá refletir na assistência ao paciente. Além disso, o profissional que é bem acolhido sente-se seguro para realizar seu trabalho e, também, buscar autonomia dentro do cenário prático em que está inserido.

Ainda com o foco na recepção no campo de trabalho, podemos ver nos relatos que muitos membros da equipe demonstraram certa resistência à figura do recém-formado, desconfiando do seu preparo para a atuação como profissional. Os relatos mostram ainda que foi necessário um período de paciência e trabalho para que a equipe se habituasse ao novo membro, como demonstrado abaixo:

A equipe dos técnicos foi bem complicado [a aceitação], tinha técnicos que fingiam que eu não estava ali, se eu falava parecia que não era ninguém. Então, eu levei um tempo, vamos dizer um mês até quase dois meses para conseguir conquistar algumas pessoas, para adquirir meu espaço lá dentro da unidade e para provar que eu realmente estava lá para fazer parte da equipe e que eu sabia alguma coisa. Então eu tive que provar isso para eles, pegando junto, mostrando que eu sabia trabalhar. (E4)

A recepção dos funcionários é sempre aquela coisa, todo mundo te olha como se você não soubesse nada, te testam esperando que vocêsaiba tudo. Então lógico a gente fica deslocado, você não conhece ninguém, você não sabe em quem pode ter mais confiança, essas coisas, mas logo depois de um mês ou dois você já está habituada, eu já me habituei, foi mais tranquilo. (E9)

0 relacionamento conflituoso em um ambiente de trabalho é visto como um obstáculo na prática profissional. Nesse contexto, torna-se importante que a equipe saiba conviver com as diferenças e individualidades de cada pessoa, visto que todos trabalham em prol de um objetivo comum. Quando isso acontece, cada membro do grupo sente-se seguro ao desenvolver sua atividade no campo de prática, refletindo em ações que buscam melhorias e o crescimento da instituição.?

Além disso, convém destacar que o apoio da equipe prestado ao profissional permite a ele desenvolver um sentimento de satisfação pessoal, no qual é preservada e estimulada a comunicação interpessoal, fortificando o respeito e compreensão entre os sujeitos envolvidos. ${ }^{8}$

Em relação às facilidades encontradas na inserção no campo de trabalho, destacamos relatos referentes à utilização da sistematização da assistência na atuação profissional, sendo uma importante contribuição do curso, como se observa nos relatos seguintes:

Ter aprendido metodologia na graduação facilitou muito a minha inserção. Eu vejo que tem gente que entra aqui de outras universidades que não conseguem se adaptar, demoram em conseguir fazer as coisas. (E6)

Pela experiência das outras enfermeiras que têm lá, que se formaram em outras universidades, elas talvez não tenham essa mesma visão de registro em prontuário que eu tenho, eu sempre procuro registrar muita coisa, fazer as consultas em forma de SOAP [forma de registro da assistência de enfermagem] e eu vejo que essas outras enfermeiras não têm essa mesma conduta. (E2)

A Sistematização da Assistência de Enfermagem (SAE) em um cenário prático permite ao profissional ampliar seu campo de visão perante os cuidados prestados ao paciente. 0 processo de organização auxilia no desenvolvimento de metodologias interdisciplinares e humanizadas da assistência. A SAE no campo de trabalho permite ao enfermeiro maior autonomia no cuidado, além de garantir a segurança dos dados por meio do registro em prontuário, permitindo uma continuidade no processo de cuidado e realizando uma aproximação entre o profissional e paciente. $^{9}$

Outra facilidade apontada foi a vontade de aprender no início da carreira profissional, buscar o conhecimento e questionar a prática realizada, como destacado nos relatos abaixo:

Facilidade (no começo da carreira) eu acho que é a vontade de aprender, essa coisa de procurar aprender. (E9)

Facilidade na inserção eu acho que é a busca pelo conhecimento prático. Tu tens que meter a mão na massa para ti saber fazer, só no momento em que tu praticas é que tu geras questionamento, mas por que isso tem que ser feito assim? São questionamentos que a gente faz depois de a gente ter a experiência, na aula teórica tu não vais ter esses questionamentos. (E15)

A educação é considerada como algo fundamental na vida; a construção dos saberes permite ao homem a adaptação ao meio em que vive. A busca constante pelo desenvolvimento do conhecimento no campo profissional é movida pelo aperfeiçoamento pessoal e exigência no 
campo de trabalho, e ambas almejam novas informações e sua aplicação no cenário prático. ${ }^{10}$

Diante disso, o acúmulo de experiências profissionais ocorre por meio de novos desafios na prática, acontecendo paralelamente diante da necessidade de cada situação. Sendo assim, cabe ao sujeito inserir-se no processo educativo, agindo com consciência crítica-reflexiva, a fim de questionar a prática implementada, buscando sanar as suas duvidas por meio da investigação e integração dos seus conhecimentos teóricos com a prática. ${ }^{10}$

Em relação às dificuldades encontradas, houve diferentes pontos de vista. Houve relatos em que foi apontada a dificuldade de aplicar uma conduta adequada, de acordo com 0 aprendizado da graduação, devido às limitações apresentadas pelo campo de trabalho. Nesses relatos também foi observada a vontade de mudar a realidade para o que considerava correto:

Por um lado é bastante frustrante, porque a gente aprende o certo, como a gente deve fazer, e a gente quer se formar efazer o certo, mas encontra tantas limitações em alguns lugares que ou acaba fazendo igual ou tenta mudar. Eu acho que eu ia ser uma pessoa que ia tentar mudar um pouco aquela realidade para o que é correto e para o que a gente aprende na graduação que eu acho que é possivel, mas é bem difícil. (E7)

As limitações ao profissional em um ambiente de trabalho podem constituir-se de um elemento estressor em seu cotidiano, o qual aumenta na medida em que se percebe o nãoatendimento das expectativas criadas em seu plano de prática. ${ }^{11}$

Houve quem levantasse como dificuldade o fato de sair das atividades teórico- práticas da Universidade, onde não era comum a falta de materiais, de recursos humanos e, até mesmo, do apoio da equipe, para um universo contrário, no qual era necessário lidar com a falta de recursos, como pode ser observado no relato abaixo:

Esse hospital que eu trabalhei era particular, então falta material, falta funcionário, falta tudo, então é complicado, que tu sai da universidade que você tem apoio de todo mundo e vai para um lugar que você não tem apoio de ninguém; então isso é mais complicado. (E9)

A ausência de materiais em um campo prático causa frustração aos profissionais inseridos no mercado de trabalho, visto que eles, ao se depararem com tal situação, precisam improvisar no momento da implementação do seu cuidado, gerando um sentimento de insatisfação em relação à assistência prestada ao paciente. ${ }^{11}$

Para que o cuidado prestado seja efetivo, é importante que o número de profissionais supra as necessidades da instituição. Tal quantitativo deve atender às características de cada local de trabalho, de modo a garantir ao profissional o desempenho de suas atividades de maneira segura e competente, além de evitar a sobrecarga e o estresse do profissional. $^{8}$

Outra dificuldade encontrada no início da carreira foi a falta de preparo para liderar e supervisionar uma equipe, pois, como recém-formado, a pouca experiência profissional acaba influenciando nesse processo que necessita de prática:

O que eu senti bastante dificuldade no começo (da carreira) foi em relação à liderança de equipe, supervisionar a equipe, porque isso é uma coisa que a gente aprende um pouco, bem pouco de teoria na universidade, mas a gente não tem nenhuma experiência prática disso. (E13)

0 conceito de liderar em um campo de trabalho consiste na resolução de conflitos nos quais o líder busca o princípio da equidade ao tomar decisões. Além disso, cabe ele, diante das suas ações, atuar com ética, respeitando a lei do exercício profissional. 0 enfermeiro que coordena uma equipe tem o intuito de buscar a participação de todos, a fim de que sejam atendidas às demandas do campo prático concomitante com a satisfação pessoal de cada membro envolvido. ${ }^{12}$

0 profissional que lidera uma equipe pode encontrar dificuldades em seu campo de trabalho. Quando o processo de liderança é visto pelo grupo como ineficaz, desenvolvese um questionamento sobre aa capacidade de quem os coordena. 0 desafio do enfermeiro diante das situações cotidianas vivenciadas em seu cenário prático é desenvolver uma postura que demonstre segurança e autonomia frente à equipe que é supervisionada, com o objetivo de incentivá-la e orientá-la na execução de suas atividades. ${ }^{13}$

Alguns dos entrevistados ingressaram no mercado de trabalho como docentes. Sob esse aspecto, pelas abordagens, observa-se que a recepção dos alunos e professores foi favorável para a adaptação no campo de trabalho. Também, a idade foi um fator relevante, sendo necessário que o egresso demonstrasse segurança e postura ao interagir com os alunos:

No começo eles (alunos) acham que tu és novinha, que tu tem a face de aluna, acabou de sair do curso. Tem que ter bastante postura, ser bem séria e mostrar que tu sabes. Não mostrar insegurança, mostrar o que tu conhece e quando não sabe também não vai mentir, mas ter postura ética. Todos eles me trataram muito bem, com respeito, tudo. Foi bem tranquilo. (E3)

Os alunos me aceitaram bem. Inclusive no [curso] técnico tinha bastante gente mais velha, assim com 


\section{Inserção no mercado de trabalho}

Jesus BH, Gomes DC, Spillere LBB, Prado ML, Canever BP

idade para ser minha mãe, então inicialmente eu pensei "nossa vai ser difíil para mim", mas eles me respeitaram bastante [...] (E7)

Ao se inserir no mercado de trabalho, o profissional deve enfrentar a aceitação dos sujeitos envolvidos em seu novo campo de prática. 0 processo é facilitado quando as pessoas estão abertas para o desenvolvimento de ideias e compartilhamento de informações. 0 bom acolhimento no campo de trabalho permite o fortalecimento de vínculos interpessoais, além de atuar como facilitador no momento de enfrentamento de diferentes situações vivenciadas. 0 enfermeiro recém-ingresso no mercado de trabalho, ao perceber sua aceitação, desenvolve-se dentro do cenário prático, trazendo contribuições e melhorias para a instituição. ${ }^{14}$

Apesar disso, é importante destacar que a pouca idade constitui-se em um obstáculo enfrentado pelos egressos no início de suas atividades profissionais. Portanto, o recémformado deve, por meio de situações cotidianas, compartilhar seu conhecimento, demonstrando autonomia e segurança para que seja aceito no seu atual local de trabalho. ${ }^{14}$

Em relação ao preparo para atuar como docente, os relatos demonstram que, durante a graduação, o contato com os grupos de pesquisa auxiliaram no processo de inserção. Outro aspecto observado foi a utilização de metodologias aplicadas pelos professores da universidade conforme mostram os discursos a seguir:

A minha formação me favoreceu de forma positiva para que eu pudesse me inserir agora no mercado de trabalho, pois eu tive a oportunidade de atuar na pesquisa desde a graduação. Eu fui bolsista PIBIC e assim que eu me formei entrei no mestrado, agora eu consegui uma vaga como professora substituta [...]. Então acho que toda a minha formação além da graduação contribuiu para que hoje eu pudesse ter essa oportunidade. (E1)

Eu me senti bem preparada. A metodologia que eu procurei aplicar foi a que eu tive de exemplo de algumas professoras da universidade. Então o primeiro dia que eu tive aula com eles eu cheguei na sala de aula, pedi que todos sentassem em círculo [...] expliquei como seria o cronograma das aulas, perguntei o que eles achavam de interessante, eu não procurei fazer provas, apenas provas de múltipla escolha, então eu procurei instigar mais o conhecimento [...] (E2)

Eu achei que eu teria mais dificuldade no meu emprego de ficar sozinha com um monte de aluno e dar uma aula. Foi legal. Eu fiquei bem surpresa. Os grupos de pesquisa ajudaram um pouco. Eu dei a aula, foi bem tranquilo, tudo que os alunos perguntaram eu sabia. Até quando eles veem que tu sabes, eles já te respeitam mais e participam mais da aula. (E3)

Os grupos de pesquisa existentes nas universidades atuam como base para o desenvolvimento dos programas de pós-graduação, sendo estes responsáveis pela formação inicial do pesquisador. 0 Programa Institucional de Bolsas de Iniciação Científica (PIBIC) objetiva a inserção do ex-bolsista da graduação ao sistema de pós-graduação; dessa forma, ao finalizar a graduação, ele se insere em um programa stricto senso (mestrado e doutorado), atuando, posteriormente, na docência. ${ }^{15}$

Ainda como facilitadora no desenvolvimento do trabalho docente, a metodologia aplicada durante a graduação pode influenciar de maneira positiva o novo profissional, que, ao se deparar com o mercado de trabalho, busca se espelhar em alguns professores, reforçando a ideia de que tal metodologia utilizada durante sua graduação foi eficaz.

\section{Planejando a próxima viagem: em busca da qualificação}

Em "Planejando a próxima viagem: em busca da qualificação profissional", os egressos relatam os seus projetos de qualificação profissional e a suas expectativas e planejamentos para o futuro profissional.

A busca pelo conhecimento e pela qualificação profissional foi algo bastante referido nas falas dos egressos, demonstrando a intencionalidade de aperfeiçoamento profissional e o desejo de continuar aprendendo, como pode ser observado abaixo:

Justamente por ser profissional da saúde eu acredito que a gente sempre precisa estar se atualizando, lendo, não deixar as coisas pararem. Quando eu escolhiser enfermeira eu já sabia que eu ia ter que estudar constantemente. (E2)

[...] eu acho que ninguém deve acabar um curso de graduação e ficar parado [...] e a vontade de aprender, [...], ter uma base teórica para pelo menos a prática ser mais sustentada. (E9)

O meu plano é sempre continuar estudando. O que eu quero mesmo é trabalhar com atenção básica, [...] e sempre continuar estudando, fazendo especializações na saúde da família, mais tarde talvez um mestrado. Eu não me vejo parada, ficar num emprego e só. Sempre continuar estudando porque as coisas são mutáveis [...] (E11) 
A continuidade no processo ensino-aprendizagem é algo notório nos relatos dos sujeitos citados, demonstrando a conscientização dos egressos quanto à necessidade e à importância da busca e do aprimoramento constante do conhecimento. Esses pressupostos caminham ao encontro das ideias do educador Paulo Freire, que considera o ser humano inconcluso em um contexto social:

E na inconclusão do ser, que se sabe como tal, que se funda a educação como processo permanente. Mulheres e homens se tornaram educáveis na medida em que se reconhecem inacabados. Não foi a educação que fez mulheres e homens educáveis, mas a consciência de sua inconclusão é que se gerou sua educabilidade. É também na inconclusão de que nos tornamos conscientes e que nos inserta no movimento permanente de procura que se alicerça a esperança. ${ }^{16: 58}$

Outro aspecto importante, evidenciado nas falas dos enfermeiros foi a respeito da continuidade da formação voltada para a área de atuação profissional, como pode ser demonstrado nos seguintes relatos:

O meu objetivo agora inicialmente é acabar a pósgraduação em saúde da família e estar mais preparada pra atender essa demanda [...] Eu sinto que eu ainda preciso aprofundar esse conhecimento. (E2)

Eu acredito que a gente tem que buscar o conhecimento na área onde a gente está trabalhando. Um dia talvez eu queira sair da emergência, mas hoje eu estou aqui e eu acho que eu tenho que ser muito boa no que eu faço [...] buscar conhecimento e aprimorar aquilo que eu preciso saber [....] (E6)

A formação generalista em Enfermagem oferece bases teórico-práticas sem um aprofundamento do conhecimento em especialidades. Isso deve ser um processo contínuo, que vise à qualificação profissional ao longo da vida. Assim, a Educação Permanente, como um prática cotidiana, permite aos enfermeiros adquirirem habilidades e competências que geram a reflexão e a modificação das ações, resultando no fortalecimento da profissão e melhoria da qualidade da assistência prestada, tendo a práxis como meio. ${ }^{17}$

Muitos enfermeiros expressaram em suas falas 0 desejo de realizar um mestrado e doutorado, tendo em vista a progressão salarial e a produção do conhecimento aplicada à prática profissional, como pode ser observado nas falas que seguem:

[...] é um objetivo meu fazer mestrado e doutorado, mas quero ainda trabalhar na prática, ser chamada num concurso público [...] principalmente, é um objetivo bem específico que eu quero alcançar. (E7)
[...] eu penso, sim, em fazer um mestrado, estou fazendo a especialização em oncologia a distância [...], penso em fazer o doutorado também, mas eu penso um pouco diferente, eu preciso ter experiência prática para querer estudar uma coisa e querer mudar aquela situação. Eu não quero estudar para produzir conhecimento que não interfira na prática, saber apenas uma realidade. Eu quero interferir diretamente naquilo ali que estou fazendo, o meu estudo vai contribuir para a prática, vai melhorar e vai ajudar a melhorar a prática de enfermagem também. (E15)

Em alguns depoimentos, pode-se observar o desinteresse dos egressos na realização do doutorado, pelo fato de não terem o desejo de seguir a carreira de docentepesquisadora, conforme se destaca nos trechos:,

Penso em fazer mestrado sim, porque eu acho que a gente não pode parar de estudar, mas não sei se farei o doutorado, até porque eu tenho um pouco de medo. [...] Porque, na verdade, o pessoal diz que para o salário é ótimo [doutorado], mas eu não tenho o objetivo de dar aula na graduação, não tenho o objetivo de trabalhar na academia. (E6)

\section{[...] Agora o que eu quero é continuar no Hospital $Y,[\ldots]$, mas eu quero fazer um mestrado, não sei se quero fazer doutorado, não sei porque eu não me interesso pelo meio acadêmico [...] Eu gosto mais de estar aqui vivenciando a prática, vivenciando o hospital, do que estar fazendo pesquisa ... (E9)}

Os cursos de pós-graduação stricto-sensu têm como principal foco a formação de docentes e pesquisadores, porém estudos atuais a respeito da formação de mestres em enfermagem demonstram que este consenso está em processo de transformação. Na opinião dos egressos de um curso de mestrado do sul do Brasil, a formação na pós-graduação exerceu grande importância na atuação profissional, voltada para a assistência, promovendo as mudanças significativas no cotidiano profissional. Dessa forma, deixa claro a necessidade de um preparo não somente para a vida acadêmica, mas também para a atividade assistencial, tendo em vista os programas stricto-sensu como um importante instrumento para a inserção no mercado de trabalho. ${ }^{18}$

Os egressos que estão inseridos na docência universitária ressaltaram o interesse em dar continuidade na formação acadêmica para, futuramente, atuarem como docentes do ensino superior, em destaque nos trechos seguintes:

Estou tendo uma nova fase para mim, um novo olhar, eu acho que vai contribuir com a minha 
formação na área da docência porque eu pretendo fazer doutorado e futuramente ser professora de alguma universidade. Eu acredito que vai ser uma experiência bem rica [professor universitário] e também vou atuar na prática, vou estar no centro de saúde, mais próximo da assistência, atuando com os alunos e podendo contribuir com o processo de ensino-aprendizagem deles (E1)

\section{Eu estou feliz por onde eu estou. Eu estou em uma área que eu gosto [professor universitário] e que eu quero seguir [...] Eu acho que eu estou alcançando as minhas expectativas, não estou frustrada. Eu quero seguir a área acadêmica mesmo, mestrado, doutorado, talvez uma residência. (E3)}

A atividade docente é uma prática complexa e temse mostrado como caminho para inserção do enfermeiro recém-formado no mercado de trabalho. Estudo realizado a respeito do processo de construção do conhecimento pedagógico docente, enfatiza a necessidade de tornar a formação permanente como fundamental para a docência, sendo essa uma das características dos bons professores. ${ }^{19}$

\section{CONCLUSÕES}

Ao trazer as interfaces das experiências dos egressos no processo de inserção e adaptação no mercado de trabalho, este estudo tornou possível refletir a respeito dessas vivências e do preparo da graduação para esse momento. Considerase necessário enfatizar o desenvolvimento de competências para a liderança, gestão de pessoas e relações interpessoais, durante a formação, pois, esses aspectos apareceram como elementos importantes na inserção e integração do enfermeiro assistencial na equipe. Outro aspecto a ser destacado é o preparo pedagógico desses enfermeiros, visto que há a necessidade atual de profissionais para atuar como educadores em cursos técnicos e de graduação em Enfermagem.

A resistência da equipe em aceitar o enfermeiro novato, a escassez de recursos materiais e humanos e a falta de experiência profissional prévia são limitações que podem ser enfrentadas no início da carreira. Sendo assim, ressalta-se a necessidade de qualificação para 0 enfrentamento dessas situações, de forma que as instituições de ensino invistam em uma formação voltada para a realidade prática e no desenvolvimento de profissionais críticos, criativos e com capacidade transformadora.

Cabe aqui ressaltar que o profissional deve reconhecer a importância e a responsabilidade que tem perante a construção e o aprimoramento dos seus saberes. A partir dessa conscientização, o profissional enfermeiro adota a
Educação Permanente como prática cotidiana das suas atividades, assumindo uma postura crítica e reflexiva que 0 leva a buscar as respostas para os seus questionamentos.

\section{REFERÊNCIAS}

1. Silva DGV, Souza SS, Trentini M, Bonetti A, Mattosinho. MMS. Os desafios enfrentados pelos iniciantes na prática de enfermagem. Rev. Esc. Enferm. USP.2010 jun.; 44(2): 511-6.

2. Resolução CNE/CES n. 3, de 07 de novembro de 2001. Institui Diretrizes Curriculares Nacionais do Curso de Graduação em Enfermagem. [citado 2011 jun. 22]. Disponivel em: <http://umw.ufv.br/seg/diretrizes/efg.pdf> .

3. Minayo MCS. 0 desafio do conhecimento: pesquisa qualitativa em saúde. 8. ed. São Paulo: HUCITEC; 2010.

4. Püschel VAA, Inácio MP, Pucci PPA. Inserção dos egressos da Escola de Enfermagem da USP no Mercado de Trabalho: Facilidades e Dificuldades. Rev. Esc. Enferm. USP. 2009 set.; 43(3): 535- 542.

5. Perrenoud P. Dez novas competências para ensinar. Porto Alegre (RS): Artes Médicas Sul; 2000.

6. Thofehrn MB. Vínculos profissionais: uma proposta para o trabalho em equipe na enfermagem [tese]. Florianópolis (SC): Pós-Graduação em Enfermagem, Universidade Federal de Santa Catarina; 2005.

7. Corradi EM, Zgoda LTRW, Paul MFB. 0 gerenciamento de conflitos entre a equipe de enfermagem. Cogitare enferm. 2008 Abr/Jun; 13(2): 18493.

8. Coronetti A, Nascimento ERP, Barra DCC, Martins JJ. 0 estresse da equipe de enfermagem na unidade de terapia intensiva: 0 enfermeiro como mediador. ACM arq. catarin. med. 2006 Out/Dez; 35(4): 36-43.

9. Nascimento KC, Backes DS, Koerich MS, Erdmann AL. Sistematização da assistência de enfermagem: vislumbrando um cuidado interativo, complementar e multiprofissional. Rev. Esc. Enferm. USP. 2008 dez;; $42(4): 643-8$.

10. Paschoal AS, Mantovani MF, Méier MJ. Percepção da educação permanente, continuada e em serviço para enfermeiros de um hospital de ensino. Rev Esc Enferm USP. 2007 set.; 41(3): 478-84.

11. Medeiros SM, Ribeiro LM, Fernandes SMBA, Veras VSD. Condições de trabalho e enfermagem: a transversalidade do sofrimento no cotidiano. Rev. eletrônica enferm. 2006; 8(2): 233-240.

12. Balsanelli AP, Cunha ICKO. Liderança no contexto da enfermagem. Rev. Esc. Enferm. USP. 2006 mar.; 40(1): 117- 22.

13. Santos I, Oliveira SEM, Castro CB. Gerência do processo de trabalho em enfermagem: liderança da enfermeira em unidades hospitalares. Texto \& contexto enferm. 2006 Jul/Set; 15(3): 393-400.

14. Mattosinho MMS, Coelho MS, Meirelles BHS, Souza SS, Argenta CE. Mundo do trabalho: alguns aspectos vivenciados pelos profissionais recémformados em enfermagem. Acta paul. enferm. 2010; 23(4): 466-72. 
15. Pires RCM. A formação inicial do professor pesquisador universitário no Programa Institucional de Bolsas de Iniciação Cientifica- PIBIC/CNPqe a prática profissional de seus egressos: um estudo de caso na Universidade do Estado da Bahia [tese]. Porto Alegre (RS): Faculdade de Educação, Universidade do Rio Grande do Sul; 2008.

16. Freire P. Pedagogia da autonomia: saberes necessários à prática educativa. 37. ed. São Paulo: Paz e Terra; 1996.

17. Ferraz F. Contexto e processo de desenvolvimento das Comissões Permanentes de Integração Ensino-Serviço: perspectiva dos sujeitos sociais pautada na concepção dialógica de Freire [tese]. Florianópolis(SC): Pós- Graduação em Enfermagem, Universidade Federal de Santa Catarina; 2011.

18. Ramos FRS, Backes VMS, Backes DS, Schneider DG, Pinheiro G, Zeferino MT, et al. Formação de mestres em enfermagem na Universidade Federal de Santa Catarina: contribuições sob a ótica de egressos. REBEN. 2010 Maio/Jun; 63(3): 359-365.

19. Backes VMS, Moyá ILM, Prado ML do. Processo de construção do conhecimento pedagógico do docente universitário de enfermagem. Rev. Latino-Am. Enfermagem.

2011 mar./abr.; 19(2): 421-8.

\section{NOTA}

${ }^{a}$ Estudo oriundo do Trabalho de Conclusão de Curso aprovado pelo Curso de Graduação em Enfermagem da Universidade Federal de Santa Catarina (UFSC). 